8 UK Parliament. How does a Bill become a Law? UK Parliament, 2019 (https://www.parliament.uk/about/how/laws/passage-bill/). Accessed 30 August 2019.

9 MIND. Mental Health Units (Use of Force Bill) becomes law. MIND, 2018 (https://www.mind.org.uk/news-campaigns/news/

mental-health-units-use-of-force-bill-becomes-law/). Accessed 30 August 2019.

10 UK Parliament. Mental Health Units (Use of Force) Act 2018. UK Parliament, 2018 (https://services.parliament.uk/bills/2017-19/ mentalhealthunitsuseofforce.html). Accessed 6 January 2019.

11 UK Parliament. Mental Capacity (Amendment) Act 2019. UK Parliament 2019 (https://services.parliament.uk/bills/2017-19/mentalcapacityamendment.html). Accessed 30 October 2019

12 UK Parliament. European Union (Withdrawal) Act 2018. UK Parliament 2018 (https://services.parliament.uk/bills/2017-19/europeanunionwithdrawal.html). Accessed 6 April 2019

13 Boateng P. Mental health services: black and minority ethnic communities. Hansard HL Deb, 2017; 787: 28 Nov.

14 Patel NB. The long-term sustainability of the NHS and adult social care Hansard HL Deb, 2018; 790: 26 Apr.

15 Crisp ENR. Nursing. 2018. Hansard HL Deb, 2018; 791: 14 May.

16 UK Parliament. Select Committees. UK Parliament, 2019 (https://www.parliament.uk/about/how/committees/select/). Accessed 30 August 2019.

17 Health and Social Care Committee. Brexit: Medicines, Medical Devices and Substances of Human Origin. Fourth Report of Session 2017-19 (HC 392). Health and Social Care Committee, 2018.
18 Secretary of State for Health and Social Care Brexit: Medicines, Medical Devices and Substances of Human Origin: Government Response to the Health and Social Care Committee's Fourth Report of Session 2017-19 (Cm 9620). Department of Health and Social Care, 2018.

19 Hollins SC. Social care: sleep-in payments. Hansard HL Deb, 2017; 787: 7 Dec.

20 Parliamentary and Health Service Ombudsman. Ignoring the Alarms: How NHS Eating Disorder Services are Failing Patients (HC 634). Parliamentary and Health Service Ombudsman, 2017.

21 O'Shaughnessy JR. Eating disorders: written answer - HL4189. Hansard HL Deb, 2017; 21 Dec, cW.

22 UK Parliament. All-Party Parliamentary Groups. UK Parliament, 2019 (https://www.parliament.uk/about/mps-and-lords/members/apg/). Accessed 30 August 2019

23 All-Party Parliamentary Group on Mental Health. Progress of the Five Year Forward View for Mental Health: On the Road to Parity. Rethink Mental Illness/Royal College of Psychiatrists, 2018

24 NHS Leadership Academy. Healthcare Leadership Model. NHS Leadership Academy, 2019 (https://www.leadershipacademy.nhs.uk/ resources/healthcare-leadership-model/). Accessed 27 July 2019.

25 Moberly T. "We're on the same side, really": medical profession turns to soft power to influence policy. BMJ 2019; 364: 1707.

\title{
AGAINST THE STREAM
}

\section{Why hasn't neuroscience delivered for psychiatry? ${ }^{\dagger}$}

\author{
David Kingdon (10
}

BJPsych Bulletin (2020) 44, 107-109, doi:10.1192/bjb.2019.87

Mental Health Care Delivery, University of Southampton, UK

Correspondence to David Kingdon (dgk@soton.ac.uk)

First received $10 \mathrm{Jul}$ 2019, final revision 24 Nov 2019, accepted 4 Dec 2019

(c) The Author 2020. This is an Open Access article, distributed under the terms of the Creative Commons Attribution licence (http://

creativecommons.org/licenses/by/4. $0 /$ ), which permits unrestricted re-use, distribution, and reproduction in any medium, provided the original work is properly cited.
Biological research has produced major advances in our understanding of our bodies and, where systems go wrong, is producing remedies to address these, but it has yet to do the same for the mind. This is because no causative biological evidence has been found for the major mental disorders in contrast to the wealth of psychosocial findings. This disparity in regard and resource needs to be addressed.

Declaration of interest D.K. has received grants for psychosocial research and royalties for books on psychosocial interventions.

Keywords Psychosocial; neuroscience; research; mental disorder; mental health services.
Neuroscience and genetic research findings have made major contributions to the understanding of a range of disorders. Substantial advances have been possible over the past two decades in the treatment of migraine (triptans),

'See this issue. multiple sclerosis (beta interferon, copolymer, fingolimide and dimethyl fumarate), acute stroke (tissue plasminogen activator) and epilepsy (rapamycin). Genetic research is now delivering on its promise to transform therapeutics for blood disorders and 'gene silencing' for porphyria. Dementia research has developed an understanding of the neurological basis for these disorders. 
In contrast, the major mental illnesses psychosis, bipolar disorder, anxiety disorders, anorexia nervosa and depression have proved remarkably resistant to similar developments. Unfortunately, it is still not possible to cite a single neuroscience or genetic finding that has been of use to the practicing psychiatrist in managing these illnesses despite attempts to suggest the contrary. ${ }^{1}$ Border $e t a l^{2}$ recently concluded, for example, that there was 'no support for historical candidate gene or candidate gene-by-interaction hypotheses for major depression across multiple large samples'. Imaging has provided no new clinically applicable insights. Immunology may be relevant to psychosis, but findings have yet to be replicated or treatments shown to be effective. Biochemistry and even pharmacology have paused with most drug companies leaving the area. ${ }^{3}$ Rather than neuroscience research, serendipity or lateral thinking remain the key tools in psychotropic drug discovery.

Why this discrepancy? Is parity of esteem the issue? Has there, in fact, been a lack of funding for severe mental illness compared with neurological disorders? That may be the case and, for example, conflation by the Medical Research Council's research funding into 'mental and neurological disorders' initially concealed this relative discrepancy. ${ }^{4}$ But is this disparity really sufficient to account for the lack of progress in finding mechanisms of mental disorders $^{5}$ or effective interventions? There has been a very significant amount of such neuroscience and genetic research into mental disorders since 'the Decade of the Brain', the 1990 s, came and went. Indeed, the genetic revolution swirls around us and is certainly not excluding mental disorders as an area for investigation. The National Institute of Mental Health, in particular, has invested heavily. There have been no comparable initiatives in psychosocial research.

There is even a new classification system based on biological concepts to tackle 'bottom-up' the lack of evidencebase for current, clinically based systems, ${ }^{6}$ but this has yet to have any clinical effect. Indeed, if a new classification of mental disorders is needed, would it not be more appropriate to develop it on the basis of existing psychosocial research that has clearly demonstrated the links between loss, threat, trauma, substance use, demographics and mental disorders, rather than on neuroscientific findings that appear, at best, to reflect the emotional consequences of these phenomena? Our psychological colleagues have already been thinking this way, but new groups using 'payment-by-results clusters' and the 'Power Threat Meaning Framework" ${ }^{77}$ have similarly to demonstrate clinical validity and reliability.

So, what about genetics, doesn't the evidence from family histories and twin studies mean that genetic influences must have a role in the genesis of mental disorders? Certainly, most mental disorders have some propensity to run in families, but much of the evidence is that this occurs for environmental reasons or possibly, from specific genetic influences on correlates, such as temperament and appearance, rather than necessarily on the disorders themselves. How individuals respond to stress may differ according to the specific events, with a combination of stress, life event and temperament/personality determining the outcome. In these circumstances, stress management and psychological treatment may be useful tools, but it is hard to envisage biological approaches, other than palliative medication, that might be relevant.

Why do we not have evidence of biological malfunctioning for severe mental disorders? Mental disorder can be caused by biological insults such as frontal lobe damage, dementia and delirium, but biological changes have yet to be shown to be relevant to the major mental disorders. Effects of childhood abuse on the brain look more interesting - there are demonstrable neurological changes and there are even suggestions that circumstances and/or therapies might reverse these. ${ }^{8}$ But these changes seem to be the consequences of the emotional, sexual and physical trauma on the individuals, certainly not the causes of the resulting mental health issues. Society therefore rightly focuses on prevention of childhood trauma, but where trauma has already occurred, provision of effective psychological approaches needs to be prioritised to meet patient choice and needs. The changes in the brain that are seen are incidental and unlikely to lend themselves to (relatively blunt) biological interventions.

The neuroscience tools we have available and indeed, those that are likely to become available in the foreseeable future, are far too insensitive to achieve an understanding of the complexities of human pathological emotional reactions. Can we really expect neuroscience to illuminate the aetiology, to take a common example, of a severe depressive illness in a recently widowed woman who has hated her husband for the last 20 years of his life? Will not a clinical interview always shed more light and lead to more effective interventions in such a scenario than an assessment based on neuroscience?

Does it matter that neurosciences continue to be such a dominant force in research into mental disorders? Indeed, why base a classification system on biology when disorders seem more to reflect human experience? The emphasis on biological as opposed to social and psychological approaches can also be disempowering, affecting perceptions of recovery and increase stigma. ${ }^{9}$ If there were biological deficits or malfunctions identified, as with dementia, pursuing remedies would make absolute sense. But where there are none, how does society decide on where to spend its research pound/dollar? Investment in psychological, social science and service delivery research has occurred but represents only a small fraction of the attention and funding of neuroscience. This is despite such research having produced evidence-based and clinically relevant changes for the practicing clinician in the psychological and social management of all the major mental disorders. Cognitive-behavioural treatments for anxiety, obsessional disorders, psychosis and bulimia are outstanding examples, endorsed internationally in treatment guidelines.

Is it not time for research to refocus resource and expertise away from the laboratory and onto these more relevant psychological and social sciences and research into clinical practice, public health and service delivery? Improving routine clinical data should be a priority. Data science can be utilised to look at the influence of life circumstances and interaction with constitutional factors and also effectiveness of duration and combinations of therapies. ${ }^{10}$ In terms of emphasis, isn't listening to patients perceptions of causation more likely to provide insights rather than 
looking down a microscope? Nothing should be completely ruled out but judgements about where it is most likely that developments will occur need to be rethought. Similarly, favoured research methodologies should be reconsidered: the dominance of the randomised controlled trial may work for medication trials, but is ill-suited for comorbid, persistent and relapsing conditions and interrelating services and complex interventions.

So, given that neuroscience research into mental disorders has been well funded, why has there been a failure to deliver? Might it not be that the difference with other areas of medicine is that there are demonstrable and incontrovertible biological abnormalities in neurological disorders, dementia and so on? No such clear causative changes exist in severe mental illnesses such as depression, anxiety, bipolar disorder and schizophrenia. Changes that do exist reflect the illnesses and tend to be dynamic, contributing to symptoms not causing them. Is it therefore not time for psychosocial research to be treated at least equally with neurosciences in psychiatry? Thoughts, feelings and behaviours certainly have effects on the brain, just as art appreciation or memorising street names does, but this does not mean that art appreciation or taxi driving are in any way likely to be changed by findings from neuroscience.

To date, biological scientists are not giving up. Insel and Landis recently reflected on 25 years of research frustration:

'One explanation is that our basic science is misguided, not relevant to clinical problems. Another explanation, which we favor, is that we do not know enough yet to translate basic neurobiology into the new diagnostics and therapeutics that will transform public health outcomes'.

But does this not seem, after more than 30 years of failure, more akin to a religious or, albeit culturally influenced, persistent strong belief than one based on scientific grounds? Just where is the rational justification for ploughing the same furrow again and again?

A focus on neuroscience in relation to psychiatry is being used to increase the specialty's scientific standing and thus attract recruits into psychiatry. But when the contribution of neuroscience to psychiatric practice is so difficult to demonstrate, could we be setting up unachievable expectations for new entrants? Would it not be more realistic to try to attract those entering medicine or already qualified doctors who might be drawn to the subject because of its, equally scientific, emphasis on psychosocial influences and relationships. Psychology as a subject has become increasingly attractive at universities and clinical psychology is recruiting very successfully. Shouldn't psychiatry continue to have a leading role in the development and use of psychosocial treatments in the tradition of Freud and Beck? Pleas to work together in potential synergies are seductive ${ }^{11}$ but the time has come to challenge the justification for such relatively high levels of investment of time, expertise and resource in neuroscience for mental disorders.

\section{Acknowledgement}

I thank the editors of the series for their very helpful comments

\section{About the author}

David Kingdon is Emeritus Professor of Mental Health Care Delivery University of Southampton, UK.

\section{References}

1 Steele JD, Paulus MP. Pragmatic neuroscience for clinical psychiatry. $\mathrm{Br}$ J Psychiatry 2019; 215(1): 404-8

2 Border R, Johnson EC, Evans LM, Smolen A, Berley N, Sullivan PF, et al No support for historical candidate gene or candidate gene-by-interaction hypotheses for major depression across multiple large samples. Am J Psychiatry 2019; 176(5): 376-87.

3 Fibiger HC. Psychiatry, the pharmaceutical industry, and the road to better therapeutics. Schizophr Bull 2012; 38(4): 649-50.

4 Kingdon D, Wykes T. Increased funding needed for mental health research. BMJ 2013; 346: f402.

5 Kingdon D, Young $\mathrm{AH}$. Research into putative biological mechanisms of mental disorders has been of no value to clinical psychiatry. $\mathrm{Br}$ Psychiatry 2007; 191: 285-90.

6 Insel TR, Landis SC. Twenty-five years of progress: the view from NIMH and NINDS. Neuron 2013; 80(3): 561-7.

7 British Psychological Society. The Power Threat Meaning Framework. British Psychological Society, 2018 (https://www.bps.org.uk/sites/ bps.org.uk/files/Policy\%20-\%20Files/PTM\%20Main.pdf).

8 Bick J, Nelson CA. Early adverse experiences and the developing brain. Neuropsychopharmacology 2016; 41(1): 177-96.

9 Angermeyer MC, Daubmann A, Wegscheider K, Mnich E, Schomerus $\mathrm{G}$, Knesebeck OV. The relationship between biogenetic attributions and desire for social distance from persons with schizophrenia and major depression revisited. Epidemiol Psychiatr Sci 2015; 24(4): 335-41.

10 Mclntosh AM, Stewart R, John A, Smith DJ, Davis K, Sudlow C, et al.. Data science for mental health: a UK perspective on a global challenge. Lancet Psychiatry 2016; 3(10): 993-8.

11 Stein DJ, He Y, Phillips A, Sahakian BJ, Williams J, Patel V. Global mental health and neuroscience: potential synergies. Lancet Psychiatry 2015; 2 (2): $178-85$

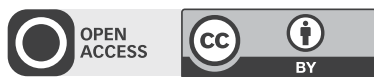

